\title{
Estimation of Bamboo Leaf Ash Waste as Partially Substitution in Ceramic Electrical Insulator
}

\section{Shanmugam Marimuthu ${ }^{1 *}$, G Sivakumar ${ }^{2}$ and K Mohanraj ${ }^{3}$}

${ }^{1} P G$ \& Research Department of Physics, Mahendra Arts \& Science College (Autonomous), Kalippatti, Tamil Nadu, India

${ }^{2}$ Centralized Instrumentation \& Service Laboratory, Annamalai University, Annamalainagar, Tamil Nadu, India

${ }^{3}$ Department of Physics, Manonmaniam Sundaranar University, Tirunelveli, Tamil Nadu, India

\begin{abstract}
In the fabrication of ceramic electrical insulator partial substitution of quartz by bamboo leaf ash by an industrial route. The overall goal of this work is to utilize the waste material in the ceramic formulation and enhances the physical properties such as bulk density, water absorption, porosity, shrinkage. The mechanical strength values of the standard ceramic insulator and 5\% bamboo leaf ash (BLA) blended specimens are 2.48 and 3.12 MPa. This result confirms that the BLA waste act as a filler in a blended ceramic insulator. The fracture surface of the specimen was analyzed through Scanning Electron Microscopy (SEM). Quartz phase and mullite formation were determined by X-ray diffraction (XRD). The electrical insulating property of the fabricated blended ceramic insulator was safe for use with a maximum of $5000 \mathrm{~V}$ evaluated. Dielectric breakdown strength is correlated with the flashover voltage. Thus, BLA waste is a suitable material for the production of the ceramic electrical insulator.
\end{abstract}

Keywords: Bamboo leaf ash; Ceramic electrical insulator; Scanning electron microscopy; X-ray diffraction; Flashover

\section{Introduction}

Triaxial porcelain forms a large base of the commonly used ceramics for both low and high tension insulation. It is considered to be one of the most complex ceramic materials and most widely studied in the raw materials, processing science, phase and microstructure evolution [1]. These materials are ceramics and generally composed of clay $\left[\mathrm{Al}_{2} \mathrm{Si}_{2} \mathrm{O}_{5}(\mathrm{OH})_{4}\right]$, give plasticity to the ceramic mixture; flint or quartz $\left(\mathrm{SiO}_{2}\right)$, maintains the shape of the formed article during firing; and feldspar $\left[\mathrm{KxNa}_{1-\mathrm{x}}\left(\mathrm{AlSi}_{3}\right) \mathrm{O}_{8}\right]$.

Bamboo leaves are one of the forest waste materials obtained as large amounts of solid waste, it is disposed of mainly by burning. Reuse of this kind of solid waste has many advantages, not least of which are the economic advantages, including job creation in companies specializing in the selection and recycling [2] of this kind of material. Utilization of this waste material such as BLA is applicable to ceramic product development. Replacement of quartz by bamboo leaf ash to develop the blended ceramic electrical insulator fabrication.

High voltage outdoor insulators used in transmission lines and substation are being subjected to various operating conditions and environments. Contamination on the surface of insulators enhances the leakage current that develops which may lead to flashover and power system outage and it is the essential element in power system [3]. Electrical insulators are used to insulate electrical wires and cables from points of support. The present investigation of the study to develop and characterize of BLA waste material in the ceramic formulation by the substitution of quartz and to estimate the potentials of materials for the fabrication of ceramic electrical insulator.

\section{Experimental Design}

\section{Raw materials}

An industrial ceramic ingredient such as clay, feldspar and quartz were purchased from M/s Oriental Ceramic Industry, Viruthachalam, Tamil Nadu. The bamboo leaves were gathered from the campus of the Annamalai University, Chidambaram, Tamil Nadu.

\section{Bamboo leaf ash process}

Dry bamboo leaves were placed inside a perforated metallic drum and ignited using charcoal and left to burn complete combustion of removing $24 \mathrm{hrs}$. The obtained ash was cleaned, dried in air for 12 hrs consequently, and then the ash calcined at $650^{\circ} \mathrm{C}$ for $3 \mathrm{hrs}$ at a heating rate of $300^{\circ} \mathrm{C} / \mathrm{h}$ in an electric furnace. The organic compounds are decomposed at $500^{\circ} \mathrm{C}$ and a large amount of [4] crystalline silica was obtained at $650^{\circ} \mathrm{C}$ then the substitution by quartz. The chemical composition of the calcined ash (BLA) was determined by X-ray fluorescence (Bruker) and its results are given in Table 1.

\section{Insulator fabrication}

Standard ceramic electrical insulator specimen (SC) was prepared using procedure ASTM C373 an industrial standard ceramic material (wt\%) such as clay $60 \%$, feldspar $25 \%$ and quartz $15 \%$. The process commenced with carrying out ratio calculations to determine the amount of BLA and quartz required to produce $15 \mathrm{wt} \%$ reinforcements consisting of 0:15, 5:10, 10:5, and 15:0 BLA and quartz weight ratios respectively. Partial substitution of quartz by calcined 5 wt\% BLA (1 for the fabrication of blended ceramic electrical insulator (QB). Each composition ( $\mathrm{SC}$ and $\mathrm{QB}$ ) was milled and water was added to the homogenous mixture separately. Then the slurry was milled for $12 \mathrm{~h}$ using ball milling and slip (slurry) was filter pressed using the pressing machine. The moisture content of ceramic electrical insulator is about $4-6 \%$ are removal of water content, then, dried for 48 hours and shaping the insulator to attain smooth surface. The dried insulator (green insulator) was sintered at $1250^{\circ} \mathrm{C}$ in a kiln and the sintered insulator are allowed to quality assessment test.

*Corresponding author: Shanmugam Marimuthu, PG \& Research Department of Physics, Mahendra Arts \& Science College (Autonomous), Kalippatti 637501, Tamil Nadu, India, Tel: + 91 9688268895; E-mail: shanmuga2131@gmail.com

Received November 09, 2017; Accepted November 28, 2017; Published December 05, 2017

Citation: Marimuthu S, Sivakumar G, Mohanraj K (2017) Estimation of Bamboo Leaf Ash Waste as Partially Substitution in Ceramic Electrical Insulator. Int J Waste Resour 7: 314. doi: 10.4172/2252-5211.1000314

Copyright: (c) 2017 Marimuthu S, et al. This is an open-access article distributed under the terms of the Creative Commons Attribution License, which permits unrestricted use, distribution, and reproduction in any medium, provided the original author and source are credited. 
Citation: Marimuthu S, Sivakumar G, Mohanraj K (2017) Estimation of Bamboo Leaf Ash Waste as Partially Substitution in Ceramic Electrical Insulator. Int J Waste Resour 7: 314. doi: 10.4172/2252-5211.1000314

Page 2 of 3

\begin{tabular}{|c|c|c|c|c|}
\hline Composition & Clay & Feldspar & Quartz & BLA \\
\hline $\mathrm{SiO}_{2}$ & 63.45 & 64.20 & 97.55 & 79.90 \\
\hline $\mathrm{Al}_{2} \mathrm{O}_{3}$ & 29.33 & 14.02 & 0.97 & 2.78 \\
\hline $\mathrm{Fe}_{2} \mathrm{O}_{3}$ & 3.17 & 0.38 & 0.27 & 0.86 \\
\hline $\mathrm{K}_{2} \mathrm{O}$ & 1.15 & 16.83 & 0.41 & 3.98 \\
\hline $\mathrm{CaO}$ & 0.33 & 0.65 & 0.23 & 7.84 \\
\hline $\mathrm{MgO}$ & 0.39 & 0.28 & 0.08 & 1.97 \\
\hline $\mathrm{Na}_{2} \mathrm{O}$ & 0.28 & 2.90 & 0.35 & 0.20 \\
\hline $\mathrm{TiO}_{2}$ & 1.57 & 0.35 & 0.04 & 0.38 \\
\hline $\mathrm{Others}^{2}$ & 0.66 & 0.26 & 0.10 & 2.09 \\
\hline
\end{tabular}

\begin{tabular}{|c|c|c|c|c|c|}
\hline Specimen & $\mathbf{P}(\%)$ & WA (\%) & $\mathbf{B D}\left(\mathbf{g} / \mathbf{c m}^{\mathbf{3}}\right)$ & $\mathbf{S}(\mathbf{\%})$ & $\mathbf{M S}(\mathbf{M P a})$ \\
\hline SC & 1.4052 & 0.6784 & 2.0503 & 5.41 & 2.48 \\
\hline QB & 1.2319 & 0.5932 & 2.0546 & 7.74 & 3.12 \\
\hline
\end{tabular}

Table 2: Physical and mechanical properties of experimental insulators.

\section{Characterization}

Physical properties such as porosity, water absorption, bulk density and shrinkage of the sintered specimens were determined by the Archimedes method with water as the liquid medium as for ASTM 37888 [5] and mechanical strength was recorded by using the universal testing machine. The microstructure of the sintered specimens was observed using scanning electron microscope (JEOL -JSM-5610LV). The major crystalline phases present in the specimen were analysed by $\mathrm{X}$-ray diffraction pattern (D/Max ULTIMA). The electrical insulation resistance and flashovers test of the specimen were examined by using an industrial test method of solid insulating material (ASTM D149).

\section{Results and Discussion}

\section{Physical and mechanical properties}

The results obtained for porosity $(\mathrm{P}) \%$, water absorption (WA)\%, shrinkage (S)\%, bulk density (BD) $\mathrm{g} / \mathrm{cm}^{3}$ and mechanical strength (MS) $\mathrm{MPa}$. The average value of the three sample results for each specimen is calculated are given in Table 2 .

The porosity and water absorption decreased with increasing of BLA content because of gradual densification increasing. It is observed that the porosity of QB is significantly lower when compared to SC and this is very advantage for the electrical insulator. The water absorption value decreased in BLA blended ceramic material. The amount of water absorbed by the material in service will affect the life of the material and even reduce the resistivity of the material. Therefore, absorbed water reduces the insulation resistance. This may be due to the presence of active silica in treating BLA. The bulk density of the sample QB is slightly higher than the SC. This relates to the vertification that contributes to an open pores amount that reduced, resulting is a more dense ceramic electrical insulator. The shrinkage increased with blended BLA higher due to less significant particles occupied the inter-particles spacing as a result of which volume is reduced [6]. The mechanical strength of the blended QB insulator (3.12 $\mathrm{MPa}$ ) becomes higher than the reference $(2.48 \mathrm{MPa})$ which is possibly suitable to the pozzolanic reaction activity of the BLA. The high mechanical strength is attributed to the reduction of cracks and flaw

\section{Phase analysis}

The XRD consequences of the experimental insulator are appearing in Figure 1. The insulator contains the greatest quartz $(\mathrm{SiO} 2)$ peak is observed around at 26 ( $2 \theta$-degree) which is a typical diffraction plot for quartz while be shy of mullite crystals $\left(2 \theta=40.91^{\circ}\right)$. In a blended QB insulator mainly characteristic diffraction peak $\left(2 \theta=60.68^{\circ}\right)$ is well known as mullite $\left(3 \mathrm{Al}_{2} \mathrm{O}_{3} \cdot 2 \mathrm{SiO}_{2}\right)$, and the new phase present in the secondary mullite crystals $\left(2 \theta=54.02^{\circ}\right)$ is distinguished.

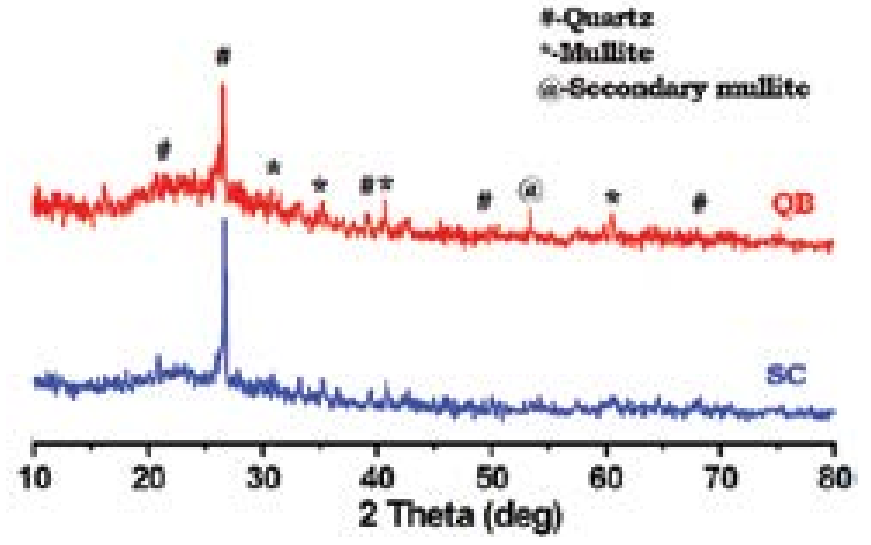

Figure 1: XRD patterns of the experimental insulators.

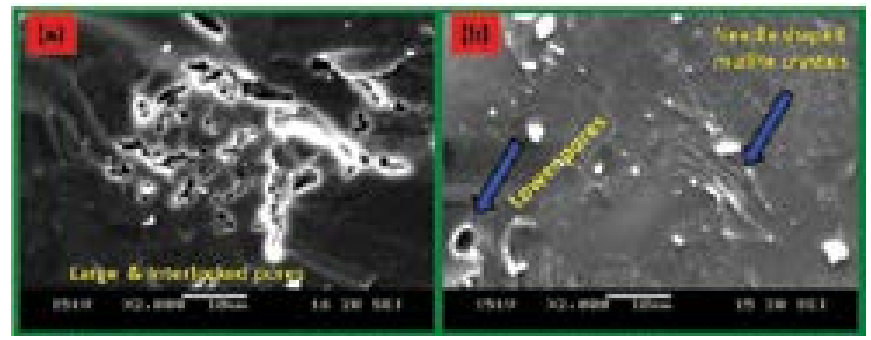

Figure 2: SEM photograph (a) SC and (b) QB of the experimental insulator.

The addition of the BLA is increased the glassy phase became supplementary obvious. It is significantly noticed that the crystalline phases formed in blended insulator, but there is a reduce in quartz content with the enhanced of mullite phase [7]. The mullite is incredibly vital phase in promoting the mechanical and dielectric properties.

\section{Morphology analysis}

Microstructural images of the insulator are in Figure 2. The SEM micrograph of SC insulator has a higher quartz nature of the standard body, contained much more, coarser and irregularly shaped porosity. The surface of the QB insulator, glassy phase and mullite structure of the sintered specimen are seen in Figure 2a. The higher porosity is observed in standard (SC) specimen which is composed of a large quantity of interlocked pores. It coincides well with the physical properties.

The size distribution of mullite whiskers becomes narrow, with a decrease due to a lack of quartz crystals. High mullite content with low quartz and micro pores become more prominent in the blended ceramic electrical insulator (Figure $2 \mathrm{~b}$ ). It is a parallel support to the $\mathrm{XRD}$ results. From the SEM image, it can be confirmed that blended QB insulator needle-shaped long mullite crystals randomly oriented in all directions [8] in the microstructure would form a three-dimensional network to reinforce the glassy matrix and reduce deforming during sintering. 
Citation: Marimuthu S, Sivakumar G, Mohanraj K (2017) Estimation of Bamboo Leaf Ash Waste as Partially Substitution in Ceramic Electrical Insulator. Int J Waste Resour 7: 314. doi: 10.4172/2252-5211.1000314

Page 3 of 3

\section{Electrical properties}

Electrical insulation resistance: The Megger device (Model No: $6250 \mathrm{IN}$ ) was used to measure the insulation resistance of the specimen. Blended $(\mathrm{QB})$ insulator has the higher value $(21.0 \mathrm{G} \Omega$ ) of insulation resistance than the $\mathrm{SC}$ insulator $(12.5 \mathrm{G} \Omega)$ at the maximum injection 5000 DC voltage. The 5\% BLA is acceptable so long as it has shown good performance in both strength and electrical insulation. The international electrical Testing Association recommends the minimum insulation resistance $500 \mathrm{Meg}$ ohms at the injection $5000 \mathrm{DC}$ voltage [9].

Flashover voltage test: The flashover voltage tests were conducted according to ANSI C29-1 for visual inspection. In this test, an alternating current voltage of $50 \mathrm{~Hz}$ frequency was applied to the test specimen in air. The voltage was initially, rapidly raised to approximately $75 \%$ of the expected flashover voltage value, and then slowly raised until a flashover occurred. It can be observed that the flashover voltage of QB $(9.92 \mathrm{kV} / \mathrm{mm})$ is much higher than the SC insulator $(8.65 \mathrm{kV} / \mathrm{mm})$. The flashover voltage was remarkably influenced by the physical properties, and the presence of higher crystalline silica content in $5 \mathrm{wt} \%$ BLA addition insulator [10].

\section{Conclusion}

Fabrication of BLA blended ceramic electrical insulator was achieved and the quality assessment of its have been investigated. The physical properties (Porosity, Water absorption and Bulk density) and mechanical strength of the blended are enhanced when compared to the standard insulator. The results indicate that the better performance was achieved by a BLA blended insulator. The BLA substitution is responsible for the occurrence of higher mullite and low quartz was confirmed by the XRD. The shape of needle-like secondary mullite crystals are seen in the blended insulator microstructure. The blended specimen has higher electrical insulation resistance was achieved than the standard one and is responsible for strength development. A higher value of the flashover voltage of the blended specimen is due to lower porosity and higher crystalline silica content. Hence, forest waste material, bamboo leaf ash is the potential candidate for electrical insulator fabrication.

\section{Acknowledgement}

The authors are grateful to Mr. Parthasarathy, Managing Director, M/s Orient Ceramic Industry, Viruthachalam for providing the ceramic materials and thanks are extended to Mr. V. Pandiyan, Deputy General Manager, M/s Global Power Research Institute, Kurinchipadi for electrical insulation resistance and flashover voltage measurement.

\section{References}

1. Olupot PW, Jonsson S, Byaruhanga JK (2010) Development and characterisation of triaxial electrical porcelains from Ugandan ceramic minerals. Cer Inter 36: 1455-1461.

2. Juan A, Medina C, Guerra MI, Morán JM, Aguado PJ, et al. (2015) Re-use of ceramic wastes in construction. Intechopen, UK.

3. Nasrat LS, Hamed AF, Hamid MA, Mansour SH (2013) Study the flashover voltage for outdoor polymer insulators under desert climatic conditions. Egypt J Petro 22: 1-8.

4. Sivakumar G, Hariharan V, Shanmugam M, Mohanraj K (2014) Fabrication an properties of bagasse ash blended ceramic tiles. J ChemTech Res 6: 49914994.

5. Guo X, Zhu L, Li W, Yang H (2013) Preparation of SiC powders by Carbothermal reduction with bamboo charcoal as renewable carbon source. J Adv Ceram 2: 128-134.

6. Mostafa NY, Shaltout AA, Abdel-aal MS, El-maghraby A (2010) Sintering mechanism of blast furnace slag - kaolin ceramics. Mat \& Des 31: 3677-3682.

7. Faria KCP, Gurgel RF, Holanda JNF (2012) Recycling of sugarcane bagasse ash, waste in the production of clay bricks. J Environ Manag 101: 7-12.

8. Ebrahimpour O, Dubois C, Chaouki J (2014) Fabrication of mullite-bonded porous $\mathrm{SiC}$ ceramics via a sol- gel assisted in situ reaction bonding. J Europ Ceram Soc 34: 237-247.

9. Emel O, Tuncel YD (2012) Evaluation of pyroplastic deformation in sanitaryware porcelain bodies. Ceram Inter 38: 1399-1407.

10. Moyo MG, Park E (2014) Ceramic raw materials in Tanzania - structure and properties for electrical insulation application. International Journal of Engineering Research \& Technology 3: 1015-1020. 